\title{
New award for therapists
}

The British Association of Dental Therapists (BADT) has announced a new award for Therapist of the Year. The winner of this year's inaugural award, sponsored by Oral-B, will receive an all expenses paid trip to New York City.

The trip is scheduled for November this year and will coincide with the prestigious Greater New York Dental Meeting. The lucky winner will be able to attend this international event, as well as the opportunity to undergo some well-earned retail therapy!

The award is just part of a comprehensive programme of support for the BADT announced by Oral-B at their Annual Scientific Meeting in April last year. Richard Everitt, Sales and Marketing Manager for Oral-B's Professional Division said, 'We're delighted to be working in partnership with the BADT. Therapists play a crucial role in preventive dentistry and given the recent changes in legislation and the increasing number of dual-qualified courses that are available, this role is likely to become even more significant.'

To enter, therapists who are fully qualified members of the BADT should submit a case study of no more than 1,500 words about a patient they have treated recently in one of the following areas: patient management, management of a medically compromised patient or those with special needs, or clinical enhancement and motivation of a patient (perio/caries).

For more details and an application form, please contact Leigh Ann Randell on 07814394620.

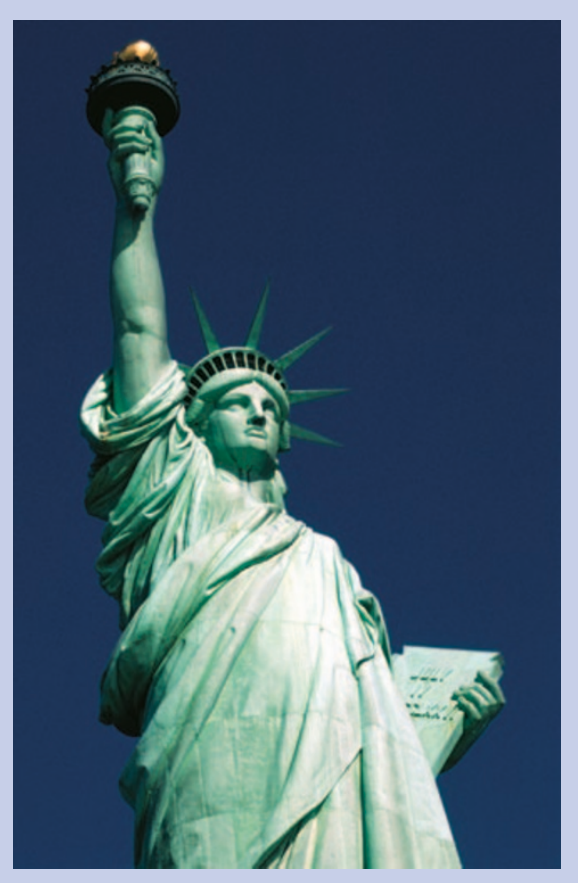

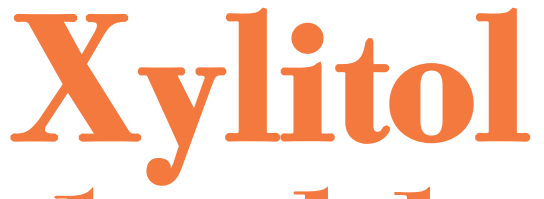
double

Xylitol, a natural sugar alternative that has been found to be beneficial to teeth, may become more widespread thanks to a new process discovered by Russian scientists.

Xylitol looks and tastes like ordinary sugar, but unlike sugar, it can help to protect against caries and the accumulation of mutans streptococci. There is also growing evidence to suggest that it can help with remineralisation of cavity lesions. Although it has been used in a few products in the UK, the sweetener has so far gone relatively unnoticed, largely due to its high cost. The new method of production uses grains left over from the brewing and spirits industries and is far cheaper and more sustainable than the way xylitol is produced at present.

James Baring of Aleron, the UK company offering the new technology, says the process could bring the cost of xylitol down to that of ordinary sugar. In addition, the new method has the benefit of producing only vegetable protein and high-quality animal fodder as by-products, with no secondary waste.

The news comes hot on the heels of the launch of the first mainstream xylitol sugar
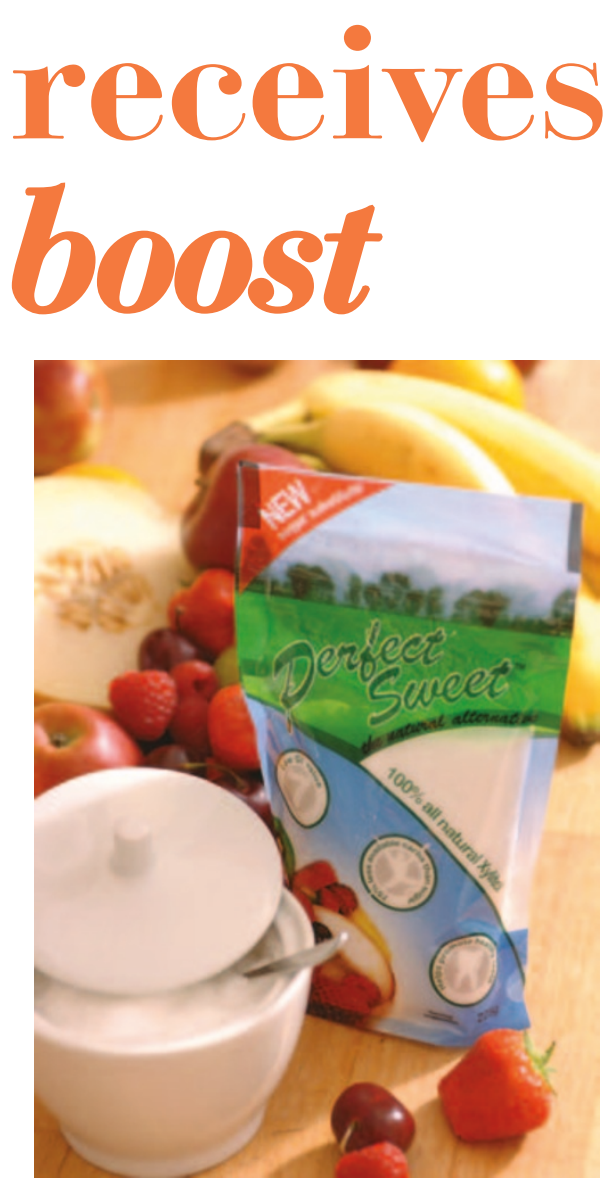

alternative, Perfect Sweet, last November. Perfect Sweet can be used in cooking and baking in the same way as ordinary sugar and is now available in many supermarkets. For more information about xylitol and Perfect Sweet visit www.perfectsweet.co.uk
New BDA Chief Executive appointed

Peter Ward has been announced as the new Chief Executive of the British Dental Association. A former general dental practitioner with extensive administrative and commercial experience, Mr Ward will take up his new role in early March and joins the BDA at a critical time for the profession and the dental industry.

Commenting on the appointment, Chair of the BDA's Executive Board Susie Sanderson said, 'Peter Ward has a real understanding of the clinical, regulatory, commercial and industrial aspects of dentistry and we are pleased to welcome him to the BDA. Dentists face great uncertainty about their future and the BDA is committed to providing the support and advice they need. Peter will give the strong leadership, knowledge and experience required to ensure the BDA delivers for the profession and their patients.'

Peter Ward said 'This is a pivotal period for dentists and a time when the BDA must be seen to provide support and leadership for the profession. I am delighted to be given the opportunity to lead the BDA at what is clearly a critical time for dentistry in the UK.'

Peter Ward takes over the role of Chief Executive from Ian Wylie, who left the BDA in December. 